\title{
"The Ekman Drain": a conduit to the deep ocean for shelf material
}

\author{
John H. Simpson • Robin R. McCandliss
}

Received: 19 December 2012 / Accepted: 3 July 2013 / Published online: 1 August 2013

(C) The Author(s) 2013. This article is published with open access at Springerlink.com

\begin{abstract}
A long (167 days) acoustic Doppler current profiler time series from the European continental slope west of Scotland has been analysed to investigate the influence of bathymetric steering on the slope current and the extent of down-slope transport in the bottom boundary layer. Within an interior region between the surface and bottom boundary layers, the direction of the flow is found to be remarkably consistent as required by the Taylor-Proudman theorem for geostrophic flow. The mean value of this interior flow direction is taken to be the effective direction of the bathymetry in controlling the geostrophic flow and so defines the rotation of coordinates required to determine along and cross-flow transports. Within a bottom boundary layer (BBL) of thickness $\sim 100 \mathrm{~m}$, the direction of the flow was deflected increasingly to the left with the mean veering angle $\sim 12.5^{\circ}$ at $12 \mathrm{mab}$ and a down-slope speed of $2.6 \mathrm{~cm} \mathrm{~s}^{-1}$. The corresponding integrated transport (the "Ekman drain") had an average value of $\sim 1.6 \mathrm{~m}^{2} \mathrm{~s}^{-1}$ over the full observation period. This down-slope flow was significantly correlated (at $0.1 \%$ level), with the stress applied by the along-slope flow although with considerable scatter (r.m.s. $\sim 1 \mathrm{~m}^{2} \mathrm{~s}^{-1}$ ) which suggests the influence of other forcing mechanisms. Combining the BBL volume transport with an estimate of the mean concentration of suspended particulate material indicates an annual down-slope flux of $3.0 \pm-$ 0.6 tonnes $\mathrm{m}^{-1}$ year ${ }^{-1}$, of which $\sim 0.36 \pm 0.1$ tonnes $\mathrm{m}^{-1}$ year $^{-1}$ is carbon. Biogeochemical measurements indicate that the
\end{abstract}

Responsible Editor: Bob Chant

This article is part of the Topical Collection on Physics of Estuaries and Coastal Seas 2012

J. H. Simpson $(\bowtie) \cdot$ R. R. McCandliss

Bangor University School of Ocean Sciences,

Menai Bridge, Wales LL59 5AB, UK

e-mail: j.h.simpson@bangor.ac.uk

Present Address:

R. R. McCandliss

BODC, National Oceanography Centre, Liverpool, UK carbon flux in the Ekman drain predominates over settlement of organic material through the water column over the slope and provides for relatively rapid delivery of material to deep water.

Keywords Slope currents · Ekman transport · Veering · Shelf-ocean exchange $\cdot$ Carbon flux

\section{Introduction}

Exchange across the continental slope, between the seas of the continental shelf and the deep sea, acts as a crucial control on the sequestration of carbon within the ocean. The hIgh levels of primary production in the shelf seas will only contribute to long-term storage if organic material is transported down the slope to abyssal depths before it is recycled in the shelf seas. Shelf-ocean exchange is also considered to play a vital role in supplying inorganic nutrients from the deep ocean to support primary production on the shelf. Consequently, there is an increasing focus on the processes involved in cross-slope exchange with a number of substantial observational programmes (Shelf Edge Exchange Processes experiments (SEEP I and II), Ocean Margin EXchange (OMEX), Shelf Edge Study (SES)) to investigate the dynamics of the slope region, within which, the very different oceanographic regimes of shelf and deep ocean adjust to each other (Huthnance 1995; Huthnance et al. 2009).

In this mutual adjustment, the steep topography of the slope and the Earth's rotation combine to impose an important constraint on the flow embodied in the Taylor-Proudman (T-P) theorem (Brink 1998) which states that all geostrophic flow over topography must be parallel to the bathymetric contours, i.e. in the along-slope direction. The flow speed may vary with depth but not the flow direction. This constraint clearly acts to inhibit exchange across the slope. Transfer across isobaths can only occur when the flow is 
not geostrophic, e.g. in the boundary layers near the surface and bottom where frictional effects are important or at high Rossby number when the strong flow is forced around tight corners. Unsteady motions like the tides, which vary on time scales shorter than the inertial period, can also avoid the bathymetric constraint although reciprocating motion in the external tides cannot, on its own, promote transport across the slope.

Where flow over the slope is barotropic as well as geostrophic, the bathymetric constraint implies that the current speed is proportional to the slope of the sea bed. Consequently, such flows tend to be concentrated over the slope with the highest speeds occurring over the steepest part of the slope.

In this contribution, we present a new analysis of data from the continental slope region west of Scotland, to elucidate the extent of bathymetric control of the flow, the structure of the slope current and transfer of material across the slope in the bottom boundary layer.

\section{Observations}

Our analysis is based on data obtained during the NERC Shelf Edge Study (1994-1996), a community programme which focused on slope processes along a section of the Hebridean slope west of Scotland (Fig. 1a). The slope topography from a high-resolution multi-beam survey of the area (Fig. 1b) is relatively regular with smooth isobaths varying little in direction and no indication of canyon-type features. The Hebridean slope is host to a substantial slope current (Booth and Ellett 1983; Huthnance 1995) which is apparently the result of forcing by the JEBAR mechanism which involves the interaction between steep topography and the meridional density gradient (Huthnance 1984; Blaas and de Swart 2000). There is evidence from drifter tracks (Burrows and Thorpe 1998) and indications from numerical models (Pingree and Le Cann 1989) that this flow can be continuous over a wide range of latitudes from the Iberian peninsula in the south to the Norwegian Sea in the north. The transport increases to the north with values 1-2 Sv along the Hebridean slope.

During the SES observational campaigns, moorings were deployed at a number of locations along the $\mathrm{S}$ line (Fig. 1) to observe the structure and seasonal variation of the slope current and the transport of suspended particulate matter (SPM) down the slope. These aims were frustrated to a considerable degree by severe disruption of the moorings due to the intense fishing activity which is concentrated over the slope region. An account of the slope current structure and variability, based on the SES mooring data, and its spatial continuity, based on shipborne acoustic Doppler current profiler (ADCP) and CTD surveys, was given in Souza et al. (2001). A study of the SPM concentrations and fluxes over the slope, based on calibrated transmissometer data from moorings and spatial surveys was reported in McCandliss (2000).

In our new analysis of the SES data, we concentrate on the ADCP mooring at S400 (Fig. 1b) which was located at a depth of close to $400 \mathrm{~m}$ in the core of the slope current and furnished the longest continuous record of currents from the SES campaigns. The flow data was acquired by bottommounted RDI 150-khHz narrow band ADCPs sampling at intervals of either 5 or $10 \mathrm{~min}$ with beam angles of $30^{\circ}$. For a bin depth of $16 \mathrm{~m}$, data coverage extended from $\sim 20 \mathrm{~m}$ above the seabed to $\sim 60 \mathrm{~m}$ below the sea surface.

In order to obtain estimates of the down-slope flux of suspended particulate material (SPM), we have combined the flow data with SPM concentrations derived from surveys using a transmissometer attached to a profiling CTD together with measurements by moored transmissometers. During ship surveys, filtered water samples of SPM were taken for gravimetric analysis in order to calibrate the optical beam attenuation data.

\section{Data analysis}

The study area is subject to significant tidal flows, mainly in the semi-diurnal band. The amplitude of the major axis $\mathrm{M}_{2}$ component of the tidal current decreases from $\sim 0.16 \mathrm{~m} \mathrm{~s}^{-1}$ on the shelf to a lower value of $\sim 0.08 \mathrm{~m} \mathrm{~s}^{-1}$ at $S 400$. These tidal variations were removed in the first stage of the analysis, by application of the 71-h Godin filter to smoothed hourly samples obtained by pre-filtering of the raw data, followed by decimation at 1-h intervals (Emery and Thomson 1998, p533).

The resulting residual currents were then subjected to coordinate rotation to give along-slope and cross-slope components of the flow.

\section{Results}

\subsection{Flow direction}

We begin the presentation of the results by considering the variation in depth, and over time, of the flow direction $\theta^{1}$ over the slope. The time vector average of $\theta$ from a continuous 82 days (YD250-332, 1995) ADCP record at S400 (Fig. 2a) indicates an almost constant value $\left(68-70^{\circ} \mathrm{T}\right)$ over much of the water column, from $\sim 80 \mathrm{~m}$ down to $\sim 280 \mathrm{~m}$, in a water depth of $\sim 400 \mathrm{~m}$. Below this interior region, from $\sim 280 \mathrm{~m}$ downwards, the current vector veers increasingly, in an anti-

\footnotetext{
${ }^{1}$ Measured positive anti-clockwise from East
} 
Fig. 1 a Location of the Shelf Edge Study. The steep gradient over the slope is indicated by the close spacing of the 200-, 400and $1,000-\mathrm{m}$ contours. The SES observations in 1995-1996 were focused on the area in the blue box. Those reported here were mainly from the $S$ line ( $r e d$ ). $\mathbf{b}$ Slope bathymetry for the central SES area and station positions. Depth contours from a high resolution swath-bathymetry survey are spaced at $25-\mathrm{m}$ intervals.

Heavy contours are at intervals of $100 \mathrm{~m}$ from 200 to $1,000 \mathrm{~m}$.

Stations are indicated by symbols: S300, empty box; S400, empty circle; S700, filled square a

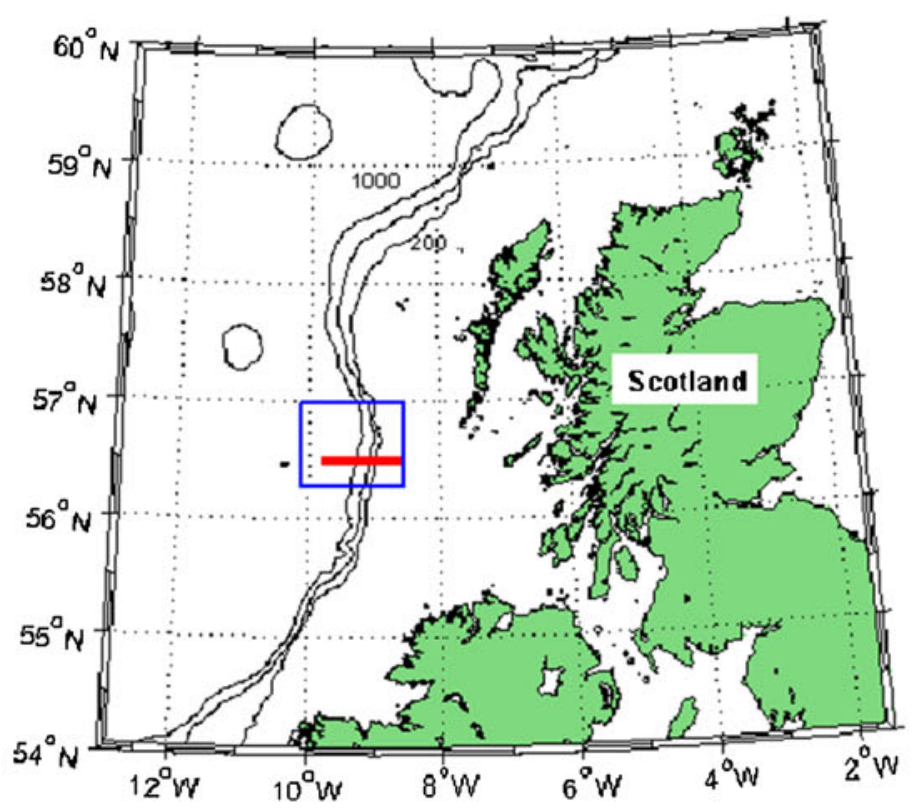

b

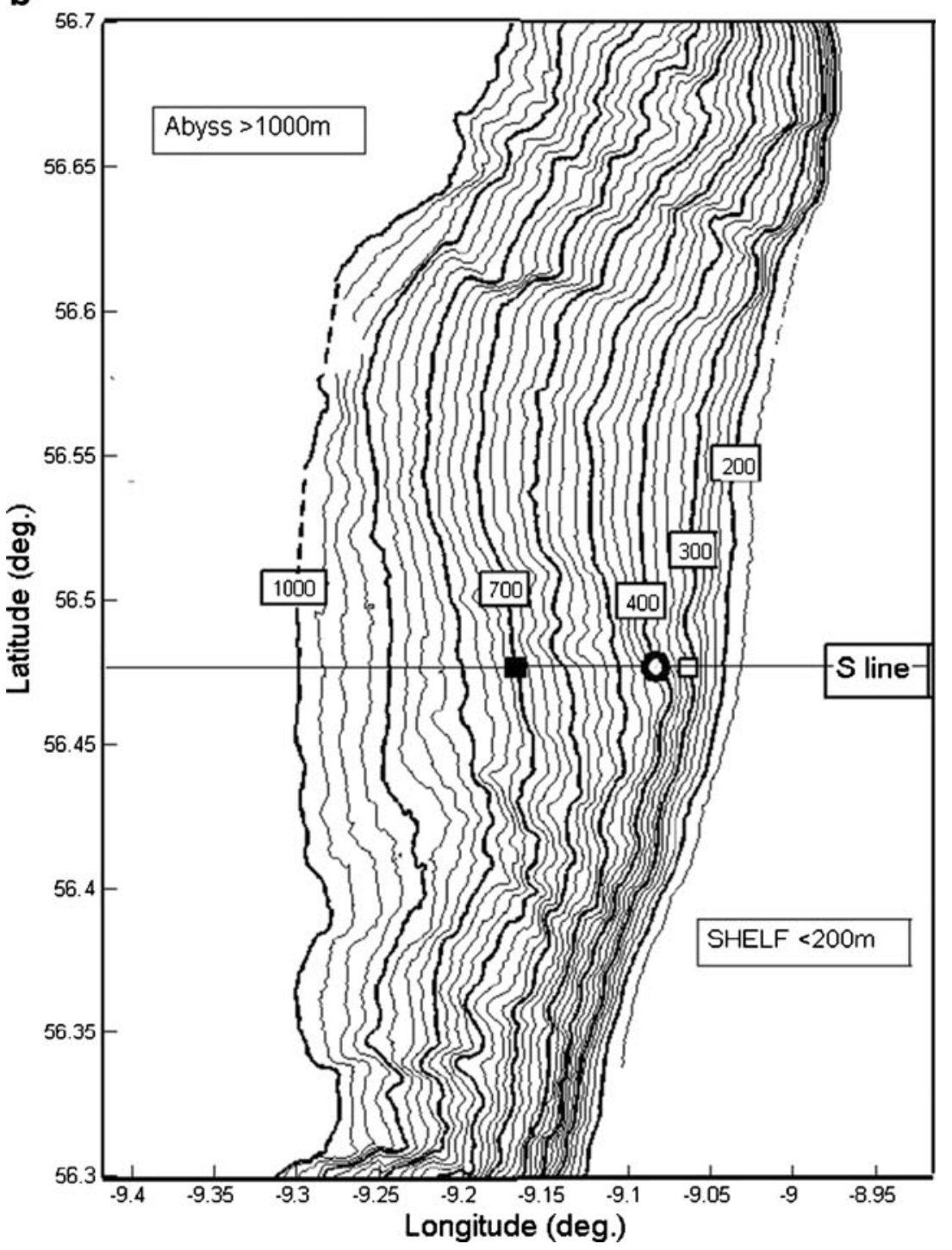




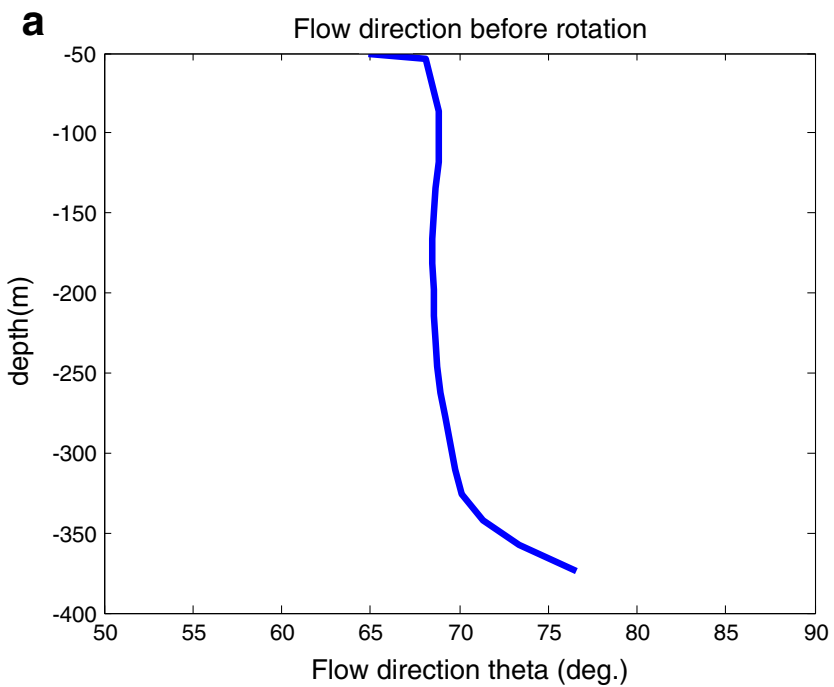

b

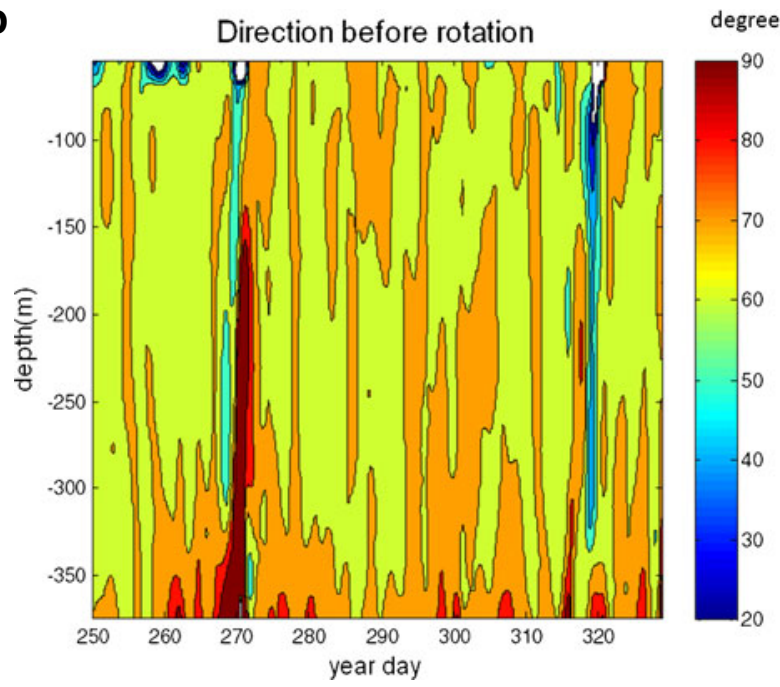

Fig. 2 Direction of the sub-tidal flow. a Time mean direction of tidally averaged flow at S400 for YD250-332,1995. The lowest ADCP bin is centred at 20 mab. Water depth was $396 \mathrm{~m}$. b Contour plot of flow direction at S400 over the same period (direction here is measured in degrees anti-clockwise from East)

clockwise sense, as depth increases, to a direction of $77^{\circ} \mathrm{T}$ at a height of $\sim 22 \mathrm{~m}$ above the seabed. This behaviour is that of Ekman veering in the frictionally influenced bottom boundary layer (BBL).

The flow direction in the interior region is also remarkably consistent in time as can be seen in the contour plot in Fig. 2b. Between depths of 100 and $300 \mathrm{~m}, \theta$ remains around the contour boundary between $60^{\circ}$ and $70^{\circ}$ except for two brief periods around days 270 and 320 when larger deviations occur. We shall return to explain these more variable episodes later but for the moment we note that for the rest of the time, the root mean square (r.m.s.) deviation of the midwater flow is $\sim 2^{\circ}$.
We interpret this constancy of the flow direction outside the top and bottom boundary layers as a clear manifestation of the operation of bathymetric control of the flow in the interior where the flow appears to be strictly geostrophic. From the TP theorem, we can then argue that $\theta$, the flow direction, is also the effective direction of the isobaths and therefore defines the appropriate direction to which we should rotate coordinates in order to ascertain along- and across-slope components of the flow. This inference provides a practical solution to the problem of determining the scale on which the topography needs to be smoothed in order to determine the appropriate along- and down- slope directions.

\subsection{Flow along and down the slope}

After rotating coordinates by the angle $\theta$, we have the mean sub-tidal velocity components along and across the bathymetry. The along-slope current (Fig. 3a) is seen to vary considerably from peak values in excess of $30 \mathrm{~cm} \mathrm{~s}^{-1}$ between 100 and $200 \mathrm{~m}$ depth to a general decrease in velocity towards the bottom boundary. At times, the slope current decreases at all depths to near zero but without any reversal of the sub-tidal flow.

Cross-slope flow (Fig. 3b) is generally much weaker with flow speeds above the BBL mostly $<3 \mathrm{~cm} \mathrm{~s}^{-1}$. Within the boundary layer, cross-slope flow is mainly down-slope with residual flow speed increasing towards the bottom and, at times, reaching values of $\sim 5 \mathrm{~cm} \mathrm{~s}^{-1}$. The average down-slope flow between 70 and $250 \mathrm{~m}$ depth over the 82-day period (Fig. 4) is negligible $\left(<0.3 \mathrm{~cm} \mathrm{~s}^{-1}\right)$. Below this, in the BBL, the down-slope speed increases steadily as in classical Ekman bottom boundary layer reaching $\sim 1.5 \mathrm{~cm} \mathrm{~s}^{-1}$ at the depth of the lowest ADCP bin which is $\sim 22 \mathrm{~m}$ above the seabed.

While the direction of the slope current is very consistent, it can be seen in Fig. 4 that its average speed varies with depth, as is allowed by the T-P theorem. The flow is, however, mainly barotropic with an average of $\sim 25 \%$ of the KE in the baroclinic component of flow as found by Harikrishnan(1998).

\subsection{Integrated transports}

A picture of the integrated transports along and across the slope is presented in Fig. 5, in which we have combined data from three consecutive deployments to produce an almost continuous time series of 167 days extending from August 1995 to late January 1996. Down-slope transport integrated over the Ekman boundary layer (Fig. 5a) is predominantly positive with a mean value over the whole period of $1.6 \pm 0.2 \mathrm{~m}^{2} \mathrm{~s}^{-1}$. The flow increases significantly ( by a factor of $\sim 2$ ) in the last month of the record to $\sim 3 \mathrm{~m}^{2} \mathrm{~s}^{-1}$. A similar 
Fig. 3 Sub-tidal flow after rotation of coordinates. Contour plots show tidally averaged velocities in centimeter per second from days 250 to 330 in 1995 for: a along-slope flow, b cross-slope flow a

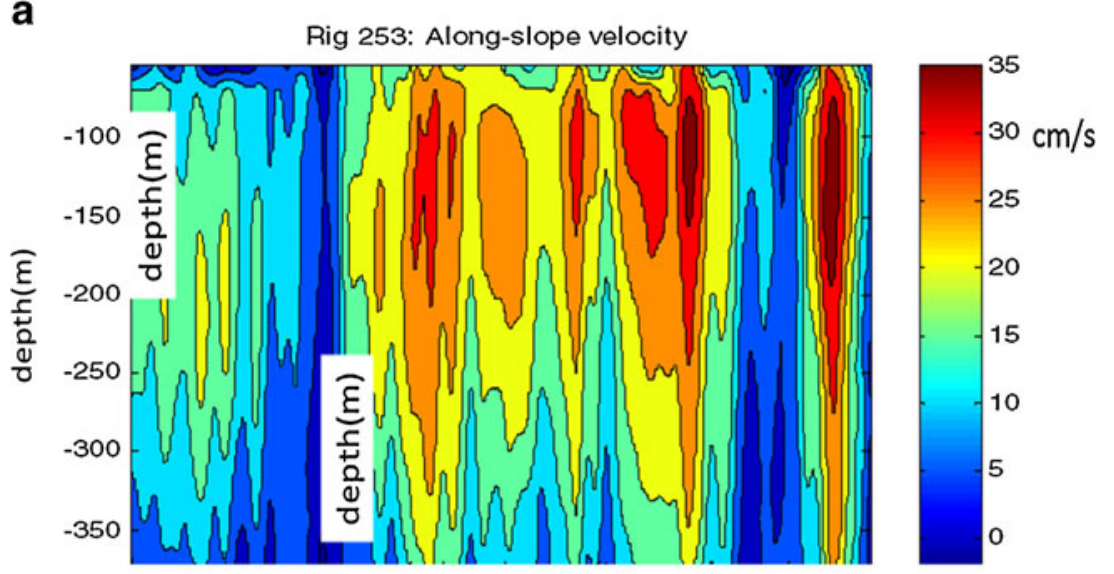

b

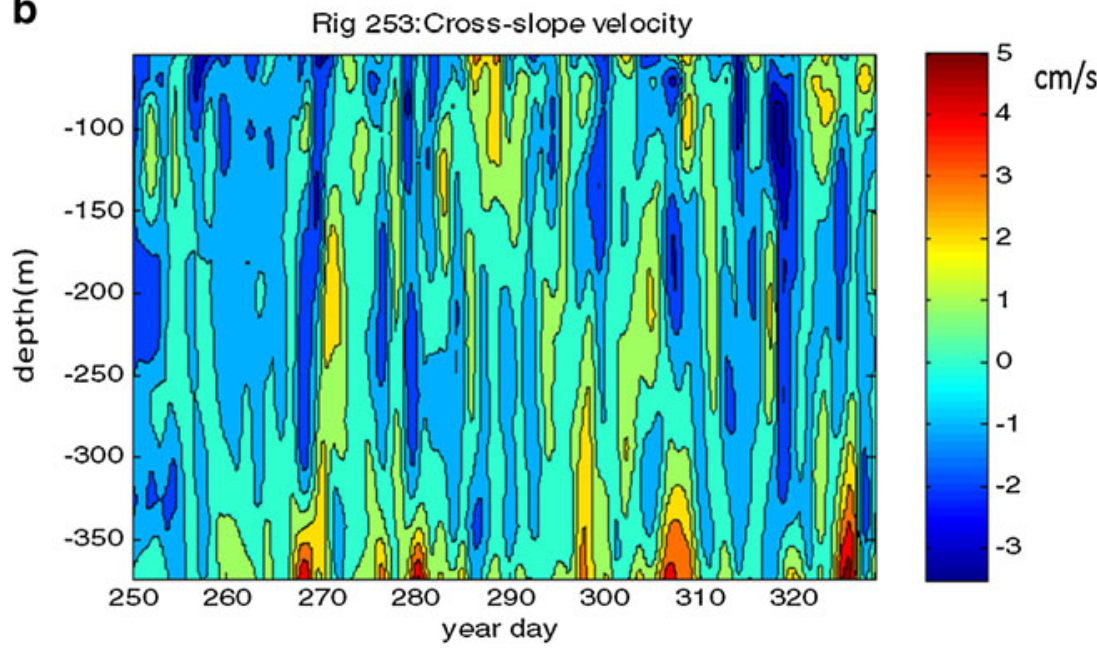

pattern is seen in the along-slope flow integrated up to a depth of $70 \mathrm{~m}$ (Fig. 5b) with the transport increasing from values $\sim 40 \mathrm{~m}^{2} \mathrm{~s}^{-1}$ in summer to $\sim 100 \mathrm{~m}^{2} \mathrm{~s}^{-1}$ in January.

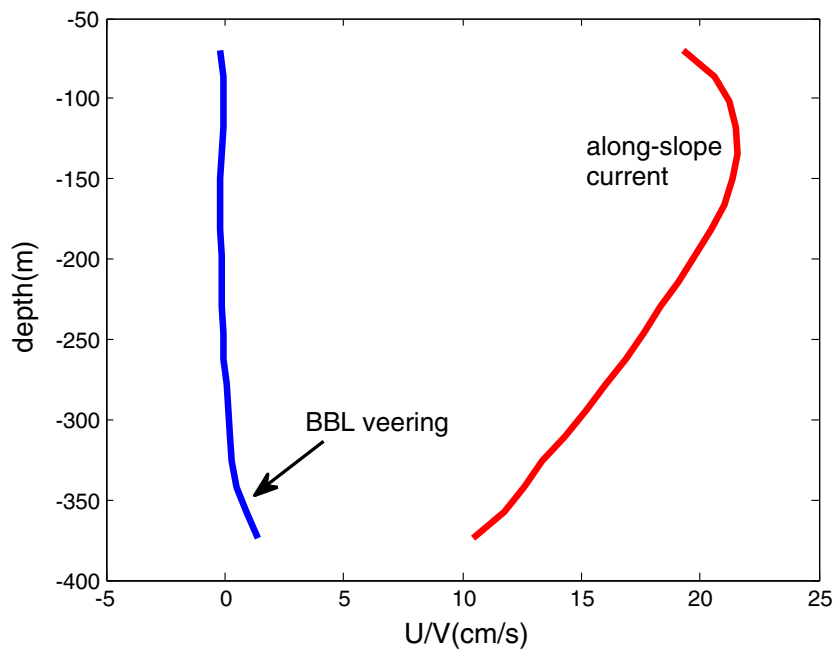

Fig. 4 Mean flow after rotation of coordinates. Plots represent alongslope and cross-slope component averages over the 82 days of data shown in Fig. 3
The direction of the flow in the interior over the whole period, shown by a plot from a representative depth of $230 \mathrm{~m}$ in Fig. 5c confirms the remarkable consistency of this aspect of the flow. The periods of deviation from strict bathymetric control occurring around days 272, 318 and 359 are seen to coincide with periods during which the flow decreased rather rapidly to very low transport levels before recovering.

According to theory, the integrated transport EK in a steady bottom Ekman layer should be related to the applied bottom stress $T_{b}$ by:

$\mathrm{EK}=\frac{T_{b}}{\rho_{0} f}=\frac{k_{b} U \sqrt{U^{2}+V^{2}}}{f}$

where $k_{b}$ is the drag coefficient for a quadratic drag law based on the depth-mean velocity components alongslope $U$ and down-slope $V$. We have tested this relation by plotting the downslope transports from Fig. 5 versus $U \sqrt{U^{2}+V^{2}}$ with both variables averaged of periods of $100 \mathrm{~h}$. The result (Fig. 6) shows a considerable degree of scatter but the regression fit is significant at the $0.1 \%$ level and has a slope which indicates a drag 
Fig. 5 Integrated sub-tidal transport and mean flow direction. Data from three deployments covering a period of 167 days at S400 are combined to show: a integrated down-slope transport EK (square meter per second) in the BBL; $\mathbf{b}$ along-slope integrated transport SlTrans (square meter per second) from the sea bed to $60 \mathrm{~m}$ below the surface. c Flow direction relative to the geostrophic flow direction at a representative depth of $230 \mathrm{~m}$ in the interior flow
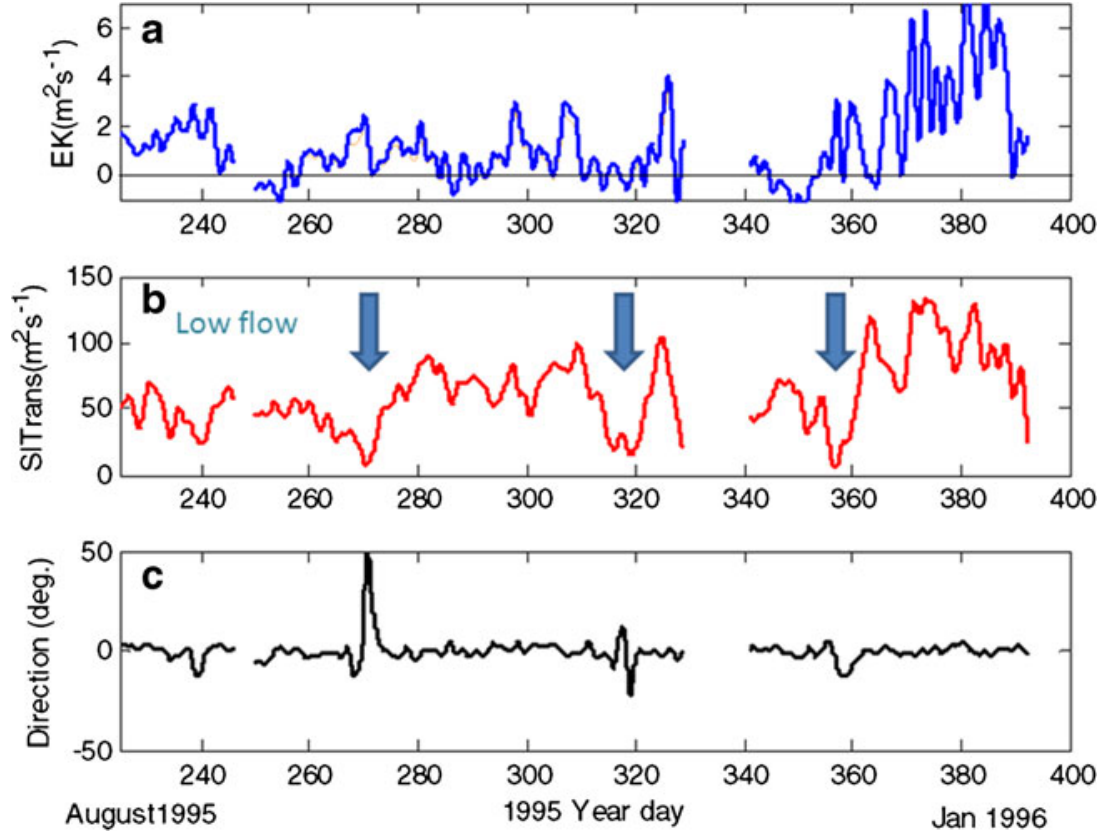

coefficient of $k_{b}=2.35 \pm 0.55 \times 10^{-3}$, which is consistent with the canonical value of $2.5 \times 10^{-3}$.

\subsection{SPM fluxes in BBL}

The concentration of SPM was measured regularly in the SES campaigns over the period May 1995-July1996 (McCandliss 2000). Surveys were conducted with a transmissometer incorporated in the ship's CTD system with

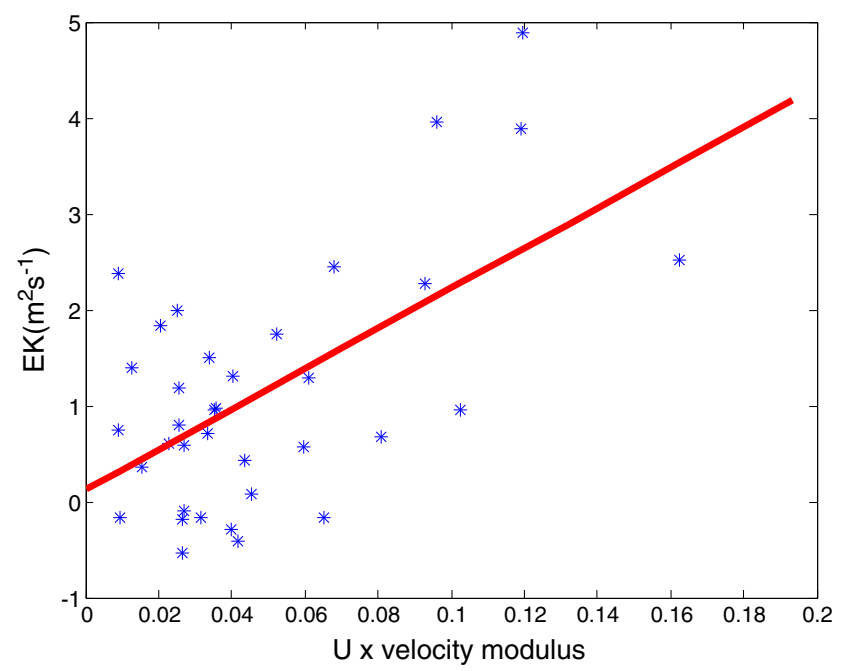

Fig. 6 Down-slope Ekman transport EK in relation to bottom stress. The abscissa is $U \sqrt{U^{2}+V^{2}}$ which is proportional to the applied stress due to vertically averaged velocity components along slope $U$ and down slope $V$. The line, which should have a slope of $k_{b} / f$ as in Eq. 1, is the least-squares fit: $\mathrm{EK}=21.0 \times U \sqrt{U^{2}+V^{2}}+0.12(t=4.27, d f=34)$ calibration by gravimetric samples. Examples of contour plots of SPM across the S line section for early summer and winter regimes are shown in Fig. 7. In both cases, there is a large interior region over the slope, at water depths $>300 \mathrm{~m}$, in which there is an SPM minimum with values are low $\left(<30 \mathrm{mg} \mathrm{m}^{-3}\right)$. In the underlying BBL there is a marked increase in SPM concentration in both May and February. This enhancement in the BBL is most marked in May (Fig. 7a) when generally higher values $\left(>125 \mathrm{mg} \mathrm{m}^{-3}\right)$ are evident in the surface and bottom boundary layers in response to enhanced primary production. In winter, on the shelf and down to water column depths of $\sim 500 \mathrm{~m}$, SPM varies little with depth contrasting with the May regime when there is strong stratification with high values $\left(\sim 150 \mathrm{mg} \mathrm{m}^{-3}\right)$ in the upper $100 \mathrm{~m}$ of the water column.

A fuller picture of the seasonal cycle of SPM variation in the BBL is shown in Fig. 8 in which all available SPM concentration data for the BBL from CTD profiles and moored instruments have been averaged over each 3-month seasonal period. For most of the year, mean values lie in the range of $50-100 \mathrm{mg} \mathrm{m}^{-3}$ with a significant drop to $\sim 30 \mathrm{mg} \mathrm{m}^{-3}$ in the autumn of 1995 . Higher values with more variability in the spring and summer were more evident in 1995 than in 1996.

Combining the flow transport data with an estimate of the long-term mean SPM concentration in the BBL $\left(\sim 65 \mathrm{mg} \mathrm{m}^{-3}\right)$, we can make a rough estimate of average SPM transport down the slope through the BBL flow.

$$
\begin{gathered}
\text { SPM Flux } \sim 1.6 \mathrm{~m}^{3} \mathrm{~s}^{-1} \times 65 \mathrm{mg} \mathrm{m}^{-3}=0.094 \mathrm{~g} \mathrm{~m}^{-1} \mathrm{~s}^{-1} \\
=3.0 \pm 0.6 \text { tonnes } \mathrm{m}^{-1} \mathrm{a}^{-1}
\end{gathered}
$$


Fig. 7 SPM concentrations across the slope on $\mathrm{S}$ line. Contours of SPM concentration (milligram per cubic metre) from transmissometer profiles. a May 1995; b February 1996 a S line CTD section May 1995

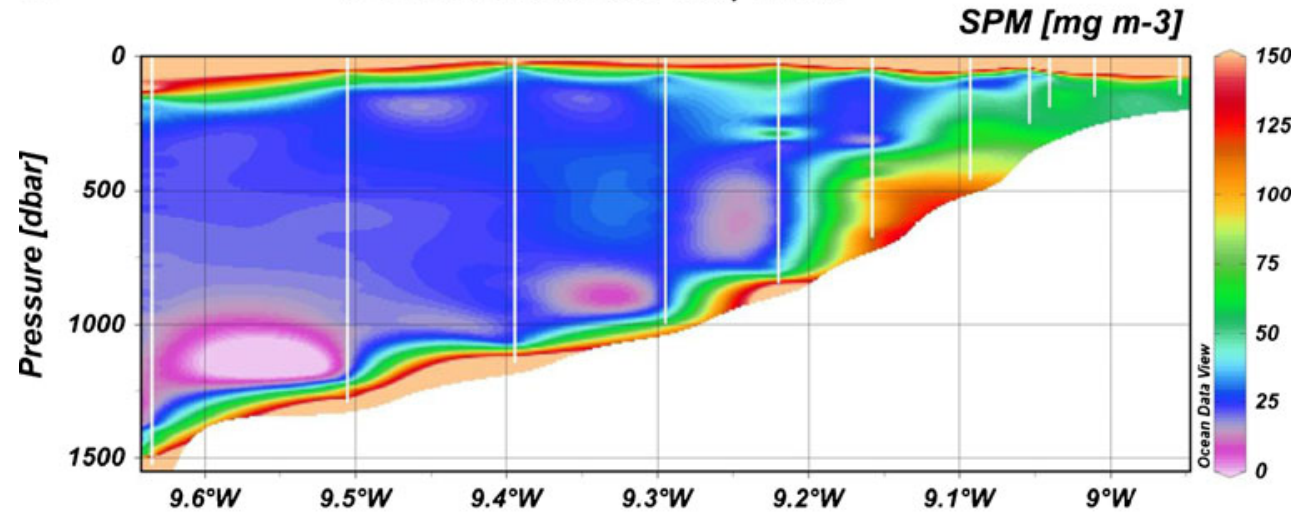

b S line CTD section February 1996

SPM [mg m-3]

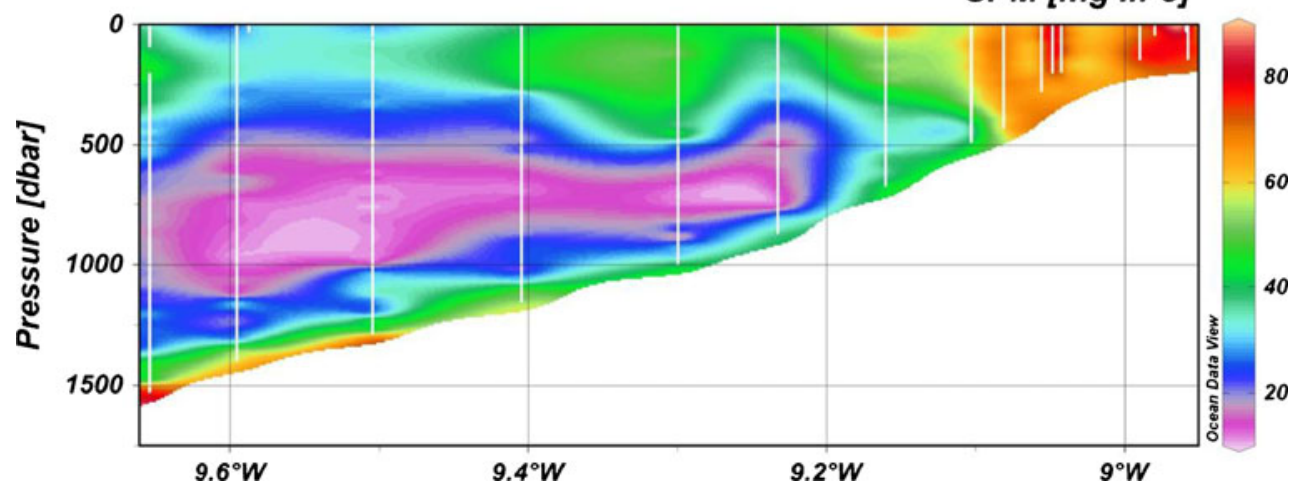

If this transport is present along the whole west European shelf where the slope current is observed $(\sim 1,000 \mathrm{~km})$, the total transport of SPM would be $\sim 3.0$ Mtonnes year $^{-1}$.

Measurements of the organic component of the SPM during the SES campaigns indicates that $\sim 12 \%$ by weight of the SPM is carbon. This implies that the BBL flux of carbon to the deep ocean is $0.36 \pm 0.1$ tonnes $\mathrm{m}^{-1}$ year ${ }^{-1}$ or a Carbon Flux of $\sim 0.4$ Mtonnes year $^{-1}$ for the $1,000 \mathrm{~km}^{-1}$ of the west European shelf.

The relative importance of this down-slope flux of carbon is indicated by other measurements made during the SES programme (Fig. 9). Estimates of the respiration in the sediments on the lower slope indicated rates of $\sim 20 \mathrm{~g} \mathrm{C}$ $\mathrm{m}^{-2}$ year $^{-1}$ while sediment trap measurements showed settlement fluxes through the water column of only $\sim 2 \mathrm{~g} \mathrm{C}$ $\mathrm{m}^{-2}$ year ${ }^{-1}$. The down-slope flux of carbon in the BBL $\left(\sim 0.4\right.$ tonnes $\mathrm{m}^{-1}$ year $\left.^{-1}\right)$, if evenly distributed over the width of the slope $(15-30 \mathrm{~km})$, would supply $\sim 10-30 \mathrm{~g} \mathrm{C}$ $\mathrm{m}^{-2}$ year $^{-1}$. The implication is that the Ekman drain flux predominates over settlement through the water column in the supply of organic material to the slope sediments. Further evidence of rapid transit down-slope comes from Chl profiles (McCandliss 2000) derived from a fluorescence sensor on the CTD. Figure 10 is an example of a profile from a
Fig. 8 SPM concentration in the BBL. Average SPM (milligram per cubic metre) in the BBL over seasonal periods from all available data at $\mathrm{S} 300$ and $\mathrm{S} 700$ from CTD-transmissometer profiles and moored instruments. Vertical lines indicate \pm 1 r.m.s. deviation from mean values

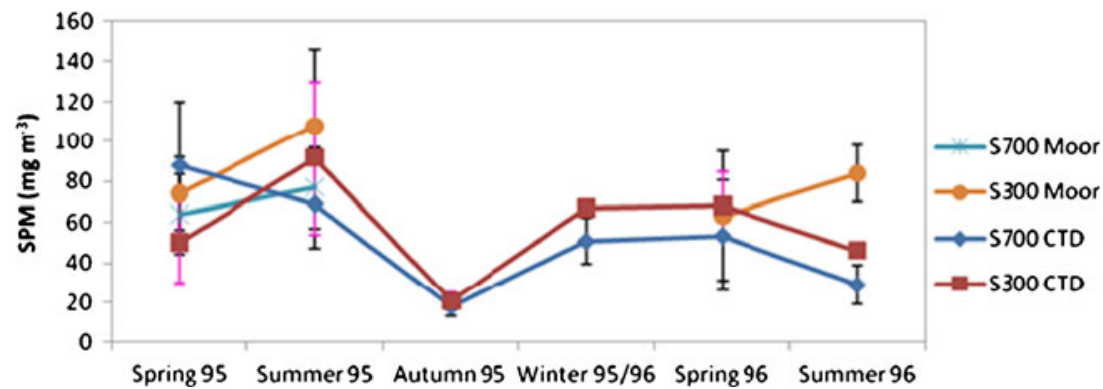


Fig. 9 Carbon fluxes and sinks over the continental slope. Schematic showing a synthesis of biogeochemical data from the SES campaigns. The flux of particulate organic carbon $(P O C)$ due to sinking of material through the water column is derived from sediment trap measurements during SES (Perez-Castillo (1999). Respiration rate estimates for the bottom sediments are based on incubation of sediment samples (M. Harvey, SAMS). Data by courtesy of G. Wolfe (University of Liverpool)

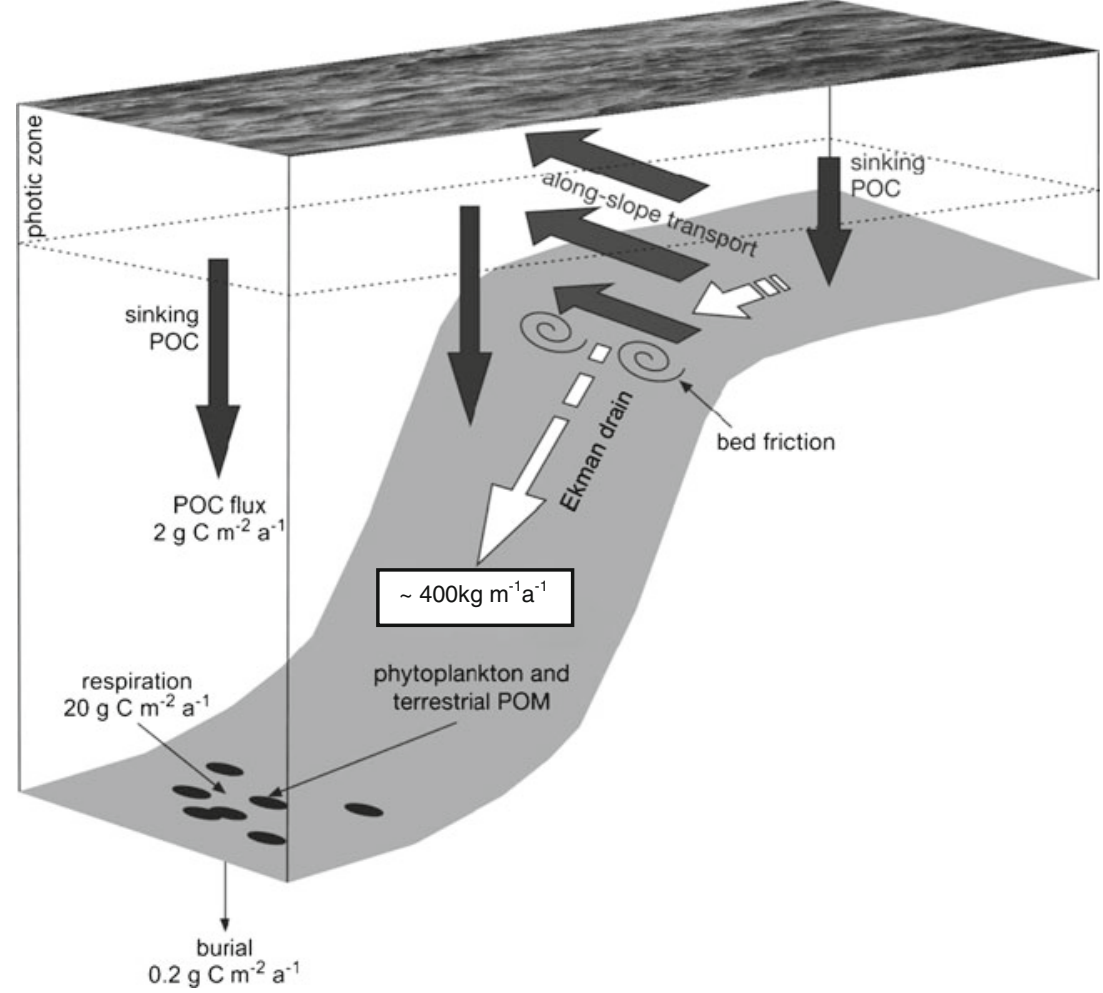

survey in May 1995 which shows a significant increase in chlorophyll concentration close to the bed in a water depth of 1,500 m. Microscope examination of near-bed samples of particulate matter (Fig. 10b) indicates the presence of intact diatom chains which implies a relatively short transit time from the surface layers. The settling velocity of such plankton is $<10 \mathrm{~m} \mathrm{day}^{-1}$ which would mean a minimum time to settle to $1,500 \mathrm{~m}$ of $\sim 150$ days. By contrast, transit downslope in the BBL at down-slope speed of $\sim 0.02 \mathrm{~m} \mathrm{~s}^{-1}$ would take $<10$ days.

\section{Summary and discussion}

Analysis of the sub-tidal currents in a long (167 day) ADCP time series from the European continental slope reveals strong bathymetric control of the flow. In the interior region, outside the top and bottom boundary layers, the flow is found to be remarkably consistent in direction in accord with the Taylor-Proudman theorem which requires steady geostrophic flow to be directed parallel to the bathymetric contours. Except during periods of very weak flow, the r.m.s. variation of flow direction in the interior was found to be $\sim 2^{\circ}$. The mean value of the interior flow direction is taken to be the effective direction of the bathymetry in controlling the geostrophic flow and is therefore, the direction to which we rotate coordinates in order to properly determine along and crossflow transports.

Approaching the bed in the bottom boundary layer, the mean direction of the flow was deflected increasingly to the left of the geostrophic flow direction. Averaging over the full 167 days of data, this Ekman veering of the current, from the along-slope direction, had a mean value of $\sim 12.5^{\circ}$ at a height of $12 \mathrm{~m}$ above bottom (mab) with a corresponding mean down-slope speed of $\sim 2.6 \mathrm{~cm} \mathrm{~s}^{-1}$. Integrating over the BBL we found significant and sustained transport with a downslope flow in the BBL averaging to $\sim 1.6 \mathrm{~m}^{2} \mathrm{~s}^{-1}$ over the full observation period. This persistent down-slope transport which circumvents the bathymetric constraint and provides a conduit for export to the deep ocean, we refer to as the "Ekman Drain" following the use of the term during the SES project (Souza et al.2001) and subsequently by others (e.g.Huthnance et al. 2009). If this flow is present along the whole west European shelf where the slope current is observed $(\sim 1,000 \mathrm{~km})$, the total volume transport would be $\sim 1.6 \mathrm{~Sv}$.

Our observational estimate of the down-slope flux in the Ekman drain may be compared to recent estimates from a numerical model designed to investigate shelf-ocean exchange at the European continental margin (Holt et al. 2009). Long-term simulations with this model indicate a net downwelling along the European shelf edge of $\sim 1.2 \mathrm{~Sv}$ which is mainly the result of onshore transport in the surface layer driven by winds in combination with an offshore 
Fig. 10 Chlorophyll and Plankton debris at $1,500 \mathrm{~m}$ depth. a Chlorophyll profile from fluorometer on CTD. b Photomicrograph of phytodetritus containing chains of the diatom Chaetoceros socialis a

\section{a} Chlorophyll $\left(\mathrm{mg} / \mathrm{m}^{3}\right)$

$0.12 \quad 0.24036-0400.60$

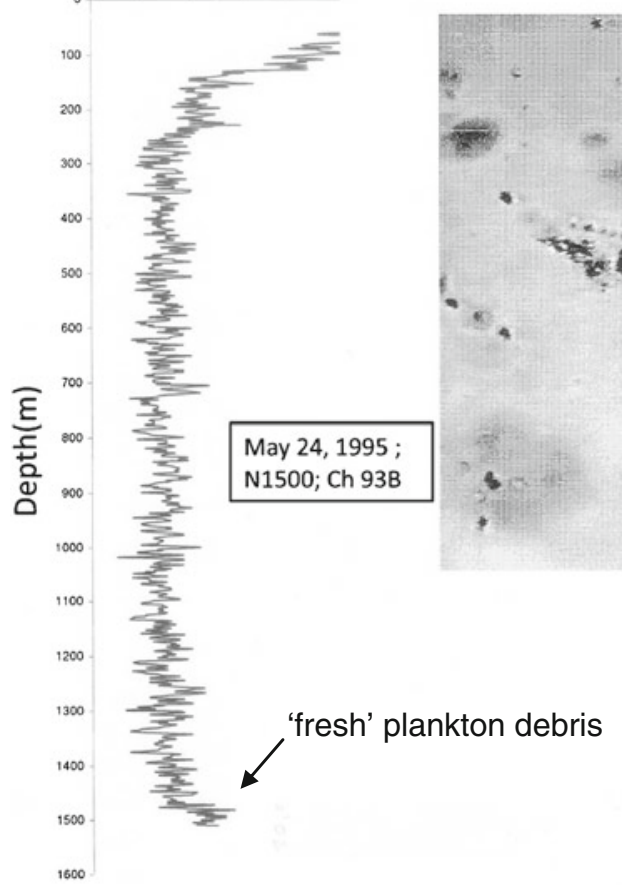

b

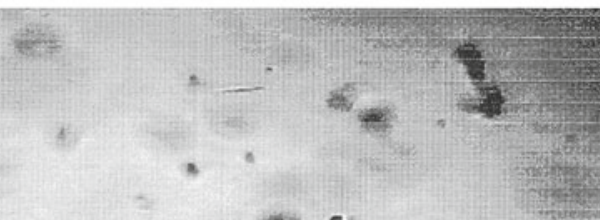

2.

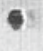

$\therefore \quad$ is $\quad \therefore \quad 10$

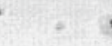

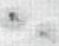

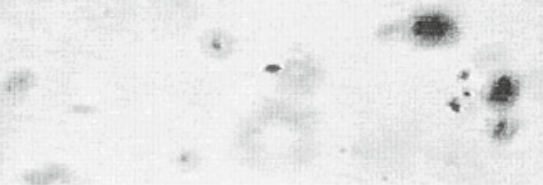

$\sim 130 \mu \mathrm{m}$

Ekman flux in the BBL. For the shelf edge west of Scotland, the model indicates a long-term average offshore transport in the BBL of $\sim 0.7 \mathrm{~m}^{2} \mathrm{~s}^{-1}$ which is less by a factor of $\sim 2$ than the observed 167 day average although, given the different spatial and time averaging of the two estimates and the considerable variability in the flow, the difference may not be significant.

The variability of the flow is evident in the comparison of down-slope transport with the frictional stress applied by the slope current (Fig. 6). While the two are significantly correlated with a regression slope which indicates a realistic drag coefficient, the considerable scatter suggests that other forcing mechanisms are at work in modulating the transport in the bottom boundary layer. Unfortunately it was not possible with the present data set, which did not extend into the surface boundary layer, to investigate the possibility of the near-bed transport responding to changes in near-surface Ekman transport forced by the wind. Future ADCP observations should be designed to adequately cover both boundary layers in order to allow the investigation of the extent to which top and bottom boundary layer transports are locally related or involve a balance over the whole length of the slope.

During the SES campaigns, some effort was made to obtain parallel time series observations of SPM and downslope transport but technical problems and equipment losses meant that only a small number of short records of valid data were obtained. Our estimates of the down-slope transport of
SPM and carbon and the associated uncertainties are, therefore, based on combining the average of the down-slope volume flux with an average SPM concentration and do not include allowance for any covariance of these two quantities. Analysis of parallel short-term records of flow and SPM (McCandliss 2000), however, indicates that the covariance term makes only a small contribution, so our estimates should be valid as representative of the levels of export in the Ekman drain. There are few comparable estimates of down-slope transports in the BBL. From measurements close to the bed in a water depth of $\sim 1,400 \mathrm{~m}$ over the continental slope south-west of Ireland during OMEX I, Thomsen and van Weering (1998) estimated a downslope particulate carbon flux of $25 \mathrm{~kg} \mathrm{~m}^{-2}$ year $^{-1}$. Assuming a boundary layer structure similar to that in our observations, this value corresponds to an integrated flux $\sim 0.6$ tonnes $\mathrm{m}^{-1}$ year $^{-1}$ which is of the same order as our estimate of $\sim 0.4$ tonnes $\mathrm{m}^{-1}$ year ${ }^{-1}$. There are, however, a number of uncertainties in both these and other estimates and there is a clear need for more observations of flow and particulate concentrations over long periods and different slope topographies to determine more fully the role of the Ekman Drain in shelf-ocean exchange.

Acknowledgments This study was supported in part by grant no. NE/ I030208/1 (FASTNEt) from the U.K. Natural Environment Research Council. We are grateful to Prof George Wolfe of Liverpool University who kindly supplied the data used in Fig. 9. We appreciated several helpful suggestions from two anonymous referees. 
Open Access This article is distributed under the terms of the Creative Commons Attribution License which permits any use, distribution, and reproduction in any medium, provided the original author(s) and the source are credited.

\section{References}

Blaas M, de Swart HE (2000) Vertical structure of residual slope circulation driven by JEBAR and tides: an idealised model. Cont Shelf Res 22(18-19):2687-2706

Booth DA, Ellett DJ (1983) The Scottish continental slope current. Cont Shelf Res 2:127-146

Brink, K. H. (1998). Deep-sea forcing and exchange processes. In: A. Robinson and K. H. Brink (eds) The sea, vol. 10: the global coastal ocean. New York, Wiley, pp. 151-170

Burrows M, Thorpe SA (1998) Drifter observations of the Hebrides slope current and nearby circulation patterns. Ann Geophys 17:280-302

Emery WJ, Thomson RE (1998) Data analysis methods in physical oceanography. Pergamon, Oxford

Harikrishnan M (1998) Flow and water column structure at the Hebridean shelf edge. PhD Thesis, University of Wales, Bangor
Holt JT, Wakelin SL, Huthnance JM (2009) The downwelling circulation of the northwest European continental shelf: a driving mechanism for the continental shelf carbon pump. Geophys Res Lett 36, L14602. doi:10.1029/2009GL038997, 2009

Huthnance JM (1984) Slope currents and JEBAR. J Phys Oceanogr 14(4):795-810

Huthnance JM (1995) Circulation, exchange and water masses at the ocean margin: the role of physical processes at the shelf edge. Prog Oceanogr 35:353-431

Huthnance JM, Holt JT, Wakelin SL (2009) Deep ocean exchange with west-European shelf seas. Ocean Sci 5(4):621-634

McCandliss RR (2000). The distribution and dynamics of particulate matter at the Hebridean shelf edge. $\mathrm{PhD}$ Thesis, University of Wales, Bangor

Perez-Castillo F (1999) Sedimentation of organic matter on the Hebridean slope. PhD Thesis, University of Wales, Bangor

Pingree RD, Le Cann B (1989) Celtic and Armorican slope and shelf residual currents. Prog Oceanogr 23:303-338

Souza AJ, Simpson JH, Harikrishnan M, Malarkey J (2001) Flow structure and seasonality in the Hebridean slope current. Oceanol Acta 24:S63-S76

Thomsen L, van Weering TCE (1998) Spatial and temporal variability of particulate matter in the benthic boundary layer at the N.W. European Continental Margin (GobanSpur). Prog Oceanogr 42:61-76 